\begin{tabular}{c} 
Volume and Issues Obtainable at Center for Sustainability Research and Consultancy \\
Journal of Business and Social Review in Emerging Economies \\
ISSN: 2519-089X (E): 2519-0326 \\
Volume 6: No. 3, 2020 \\
JSRᄃ \\
Journal homepage: www.publishing.globalcsrc.org/jbsee \\
\hline
\end{tabular}

\title{
Role of Cooperative Learning in Improving Language Proficiency and Academic Achievement in English of Elementary Students: An Experimental Study
}

\author{
${ }^{1}$ Ghazal Khalid Siddique, ${ }^{2}$ Tayyabba Yasmin, ${ }^{3}$ Mubashar Nadeem, ${ }^{4}$ Saba Farooq \\ ${ }^{1}$ Assistant Professor, University of Education, Lahore, ghazlkhalid@ue.edu.pk \\ ${ }^{2}$ Lecturer, University of Education, Lahore, tayyaba.yasmin@ue.edu.pk \\ ${ }^{3}$ Assistant Professor, University of Education, Lahore, drnadeem@ue.edu.pk \\ ${ }^{4} \mathrm{PhD}$ Scholar, University of Education, Lahore, Pakistan, sabafarooq9999@ gmail.com
}

\begin{tabular}{lr}
\hline ARTICLE DETAILS \\
\hline History \\
$\begin{array}{l}\text { Revised format: August } 2020 \\
\text { Available Online: }\end{array}$ \\
2020 & September \\
\hline Keywords & \\
Cooperative & Learning, \\
Language & Proficiency, \\
Academic & Achievement, \\
Elementary Students
\end{tabular}

JEL Classification

$I 0, I 2$

\begin{abstract}
English language, as it is employed as a common medium used for communication with people, whom native language is not understandable. In this regard, Governments of developing countries paying attention to promoting English. That require up-gradation in the curriculum, as well as, the shift of teaching methodology from teacher to student centered, are the basic requisites for making the change in the educational system possible. That provides opportunities for cooperative learning. Therefore the current experimental study was carried out to find the role of cooperative learning in promoting language proficiency and achievement with regards to English among 8th grade students, who are supposed to study in the private schools of Lahore. The 8th grade students enrolled in private schools of Lahore district implied the population of the study. Whereas, the two girls sections of the 8th class of The Educators School, Jinnah Campus, Lahore, were chosen as the sample and nominated as experimental and control groups. Before and after the intervention, English language proficiency tests (EPT) to measure the students' proficiency in English and English achievement test (EAT) to identify students' achievement in English developed by the researchers were utilized. Findings highlighted that cooperative learning is an effective teaching methodology that proves beneficial in the improvement of 8th grade students' proficiency and achievement in English. It is recommended that our teachers may use such innovative teaching methodologies in their classroom that not only promote students' involvement for discussion on the relevant topic
\end{abstract}

(C) 2020 Center for Sustainability Research and Consultancy Pakistan under a Creative Commons Attribution-NonCommercial-ShareAlike 4.0

Corresponding author's email address: $\underline{\text { s.a.waheed@uo.edu.pk }}$

Recommended citation: Siddiqui, G. K., Yasmin, T., Nadeem, M. \& Farooq, S. (2020). Role of Cooperative Learning in Improving Language Proficiency and Academic Achievement in English of Elementary Students: An Experimental Study. Journal of Business and Social Review in Emerging Economies, 6(3), 1159, 1164

\section{Introduction}

English is supposed to be an influencing factor, as it is deployed as a mode of communication from our official meetings to international scenarios, where people belonged to different cultures and contexts. In such 
circumstances, people understand each other with the help of the English language, as it is employed as a common medium used for communication with people, whom native language is not understandable (Bury \& Oka, 2017; Fujita, 2019; Ishikawa, 2017).

Governments of developing countries paying attention to promoting English, by realizing its importance, in this regard it is adopted as a compulsory subject till intermediate level (Astalini, Kurniawan, Kurniawan, \& Anggraini, 2019). The realization of modern trends and requirements is considered essential to make progress at the national level. Which demands a change in every field either related to technological trends, sociological, political, or educational system (Farooq, Tatlah, \& Butt, 2020). Upgradation in the curriculum, as well as, the shift of teaching methodology from teacher to student centered, are the basic requisites for making the change in the educational system possible. That provides opportunities for cooperative learning (Emaliana, 2017; Purba, 2018; Zarei \& Sharna, 2019).

Cooperative learning is implied as one of the approaches that are utilized by the teachers as student centered, which allows them to work in a group setting to improve their learning (Van Ryzin \& Roseth, 2018). In such a teachinglearning environment, teachers are supposed to categorize the students of the whole class into small groups. Students learn the content related to related their syllabus in group settings (Hashmi, Khalid, \& Hussain, 2020; Sharan, 2010, 2015).

Basic characteristics of cooperative learning include dependability of classmates on each other in a positive manner; allows the teacher to student and student to students discussion; assessment based on the performance of student while working in a group setting; improvement in inter as well as intrapersonal skills; and capability to work with others (Poch, Carracedo, Salan, \& Alvarez, 2019; Tran, 2014). In this learning environment, students are supposed to work mutually with their group fellows (belong to their class) for the attainment of common goals. Students cooperative effort assure the success of group work but all the members of the group assessed on the performance of the individual student (Tran, 2014)

The best way to learn a language is the practice of that particular language in our daily routine while interacting with others. Despite the teachers are considered as the role model for the students, they tried to learn and follow their students. But their proficiency can only be improved by regular practice of it. For this purpose, cooperative learning provides support to language students. Past researches are evident that cooperative is advantageous to improve the proficiency of students in the English language (Nejad \& Keshavarzi, 2015; Purba, 2018; Saleh, 2012; Suwantarathip \& Wichadee, 2010).

Saleh (2012) conduct an experimental study to identify the proficiency of female students studied in the first year after experience cooperative learning. He highlighted that cooperative learning brings positive improvement in proficiency as well as attitude towards learning of English among college students. Suwantarathip and Wichadee (2010), also carried out an experimental study to identify the effectiveness of cooperative learning on university students language anxiety and proficiency. The results of their study showed that students produced better proficiency scores at the time of the post-test after experiencing cooperative learning.

Similarly, studies carried out by (Ahmad \& Mahmood, 2010; Ghaith, 2002; Gull \& Shehzad, 2015; Tran, 2014) indicated that students secure good marks in their term exam of English after being part of the experimental group where students practiced cooperative learning.

Despite realizing the importance of the English language, students face difficulty in understanding the content of the second language as they are less proficient in reading comprehension. They are also not capable to recognize the spell after listening sound of any word. In the same pattern, they have no proficiency in grammar (Chen, 2005). To become proficient in any language students must have the capability to understand the content after reading the content matter, recognize the words and their spell after listening to them, and also must have familiarity with grammatical rules.

Researchers frequently conducted their studies to identify the effectiveness of cooperative learning on a different subject with students enrolled in different programs, but there still exists a deficiency in the literature to fully describe 
the phenomenon in Pakistani context. Therefore, the current research was intended to find the role of cooperative learning as an effective teaching methodology in the improvement of $8^{\text {th }}$ class students' language proficiency and achievement with regards to English, who are supposed to study in the private schools at Lahore district. The results of this study may prove beneficial for school teachers as well as school administration, to develop an understanding of the effectiveness of cooperative learning as a teaching methodology to promote language proficiency among students that may also prove fruitful for students for the attainment of good grades in English. Therefore, the results of this study may assist to highlight the importance of using innovative teaching methodologies in classrooms that suit the students' temperament. In order to improve their interest in learning a second language, considered as an essential requirement of the modern era. So, the experimental study was carried out to find the role of cooperative learning in promoting language proficiency and achievement with regards to English among $8^{\text {th }}$ grade students, who are supposed to study in the private schools of Lahore.

\section{Research Hypothesis}

H1: There is a significant improvement in students' language proficiency and achievement in English after learning through Cooperative learning

\section{Conceptual Framework}

In order to conduct this intervention, the experimental group was though with the help of cooperative learning, to identify the effectiveness of cooperative learning on elementary students' English language proficiency as well as improvement in their academic achievement in the subject of English. Which reflects cooperative learning as an independent variable while proficiency and achievement in English as dependent variables.

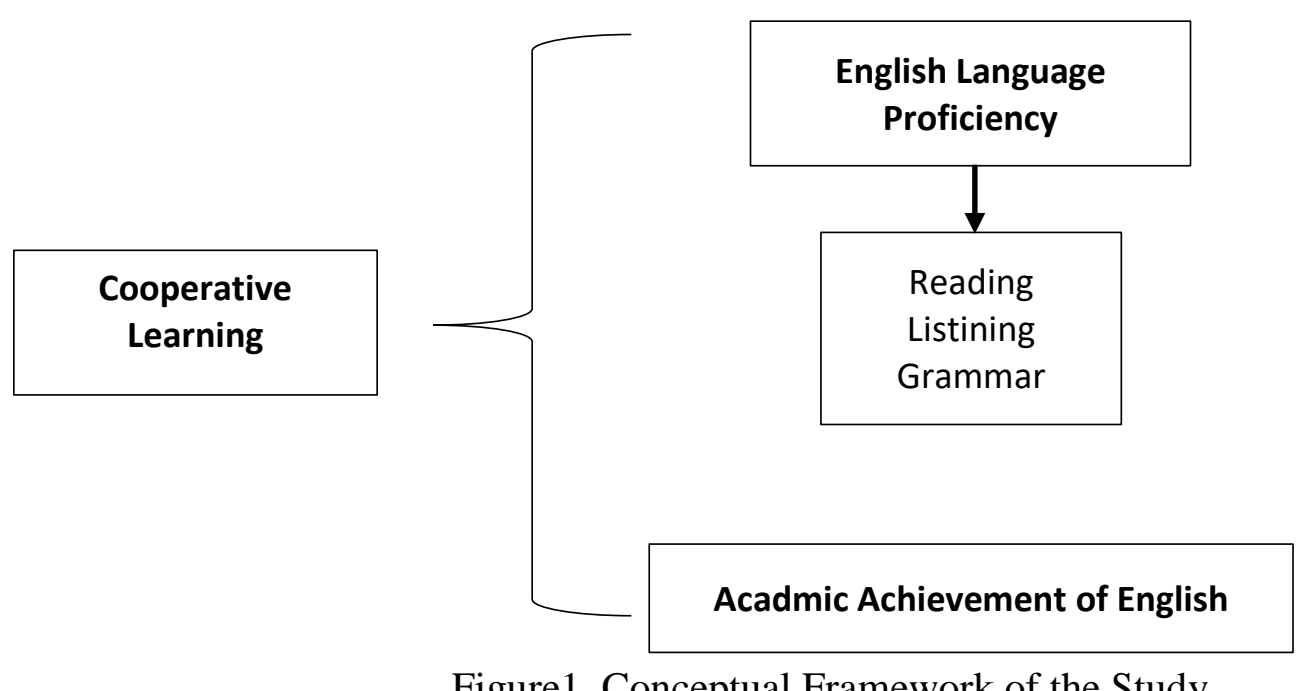

\section{Methodology}

The researchers conducted the current study with the help of non-equivalent groups pretest-posttest design of quasiexperimental research by following the positivism paradigm. Where the effectiveness of cooperative learning is supposed to be measured after its manipulation on language proficiency and achievement in the subject of English, as these two variables are deployed as dependent variables. The $8^{\text {th }}$ grade students enrolled in private schools of Lahore district implied the population of the study. Whereas, the two girls sections of the $8^{\text {th }}$ class of The Educators School, Jinnah Campus, Lahore, were chosen as the sample and nominated as experimental and control groups. The director of the school permitted the intervention, but not for splitting the class into two random groups therefore the researchers were bound to utilize the quasi-experimental design.

\subsection{Procedure of Intervention}

Cooperative learning was adopted as the teaching methodology in the experimental group, while the other group was taught through the incorporation of the lecture method. To minimize the threats of internal as well as external validity the homogeneity of groups was assured by deploying a few variables that may alter the results like: qualification, age, 
and experience of teachers; lecture timing, and place of delivering the lecture.

The intervention lasted for 2 and half months (10 weeks), six classes each week (Monday to Friday). The class strength of the experimental group was comprised of 36 students, but the results of eight students were not included in the final analysis as their attendance was less than $80 \%$. Similarly, the results of 5 students were also excluded by following the same criteria. After the training regarding the cooperative learning arranged by the teacher for the experimental group, students practice the cooperative learning throughout the intervention in small groups. Each group consisted of four students.

For effective implementation of the intervention, the following requirements fulfilled:

- All members of a group supposed to be work cooperatively with their group fellow to accomplish the assigned task, for which they helped each other to learn as well as they learned from each other.

- The teacher divided the students into groups, that shuffled at regular intervals (such shuffling of students promoted cooperative learning with other students either they are friends or just class fellows), assign them group tasks, decide the sequence of patricipations of members, allocate the material, and time duration for the accomplishment of the task.

\subsection{Instrumentation}

Before and after the intervention, English language proficiency tests (EPT) to measure the students' proficiency in English and English achievement test (EAT) to identify students' achievement in English developed by the researchers were utilized. EPT consisted of three sections related to Reading comprehension, listening skills, and grammar. Each section carried 10 multiple choice questions. EAT was also based on multiple choice questions, but it represents students' achievement in their term exams that carried 100 marks.

\subsection{Analysis of the Data}

With the Independent sample t-test, the mean difference in results of students' (belonged to experimental and control groups) proficiency and achievement in pre, as well as post test, identified. The details about the aforementioned analysis given below:

\section{Table 1}

Comparison in Students' English Proficiency before the Intervention

\begin{tabular}{|c|c|c|c|c|c|c|c|c|c|}
\hline & \multicolumn{2}{|c|}{ Experimental } & \multicolumn{2}{|c|}{ Control } & \multirow[b]{2}{*}{$\mathrm{t}$} & \multirow[b]{2}{*}{$p$} & \multirow[b]{2}{*}{$d$} & \multicolumn{2}{|c|}{ Class Interval } \\
\hline & $\mathrm{M}$ & SD & $\mathrm{M}$ & SD & & & & Lower & Upper \\
\hline Reading & 4.93 & 1.19 & 5.13 & 1.34 & -.593 & .556 & 0.16 & -.851 & .462 \\
\hline Listining & 3.28 & .80 & 3.42 & 0.90 & -.593 & .556 & 0.16 & -.568 & .308 \\
\hline Grammar & 5.52 & 0.13 & 5.50 & 0.66 & 1.000 & .321 & 0.04 & -.023 & .069 \\
\hline Proficiency & 4.58 & 0.67 & 4.68 & 0.75 & -.549 & .585 & 0.14 & -.467 & .266 \\
\hline
\end{tabular}

Table 1 reflects the value of an independent sample $t$ test, that was utilized to measure the difference in mean scores in $8^{\text {th }}$ class students' English proficiency (reading, listening, and grammar) belonged to experimental and control groups. These values highlighted that before the intervention all students equally have language proficiency, as the mean value $(\mathrm{M}=4.58, \mathrm{SD}=0.67)$ of experimental group students is almost equal with the mean proficiency value $(\mathrm{M}=$ $4.68, \mathrm{SD}=0.75)$ of the control group. Similarly, $\mathrm{t}(58)=-.549, \mathrm{p}>.05$, whereas class interval ranges from -.467 to .266 , and Cohen's $d=0.14$ which represent the small effect size.

Table 2

Comparison in Students' Achievement Results in English Before the Intervention

\begin{tabular}{|c|c|c|c|c|c|c|c|c|c|}
\hline & \multicolumn{2}{|c|}{ Experimental } & \multicolumn{2}{|c|}{ Control } & \multirow[b]{2}{*}{$\mathrm{t}$} & \multirow[b]{2}{*}{$P$} & \multirow[b]{2}{*}{$d$} & \multicolumn{2}{|c|}{ Class Interval } \\
\hline & $\mathrm{M}$ & SD & $\mathrm{M}$ & $\mathrm{SD}$ & & & & Lower & Upper \\
\hline Achievement & 68.65 & 6.67 & 69.57 & 6.47 & -.545 & .588 & 0.14 & -4.32 & 2.47 \\
\hline
\end{tabular}


The above table represents results of an independent sample t test, deployed to find the difference in mean scores in $8^{\text {th }}$ class students' English achievement through their term exams before intervention. These values highlighted that before the intervention all students achieve moderate scores in English, as $(\mathrm{M}=68.65, \mathrm{SD}=6.67)$ of experimental group students is almost equal with the mean achievement value $(\mathrm{M}=69.57, \mathrm{SD}=6.47)$ of the control group. Similarly, $\mathrm{t}(58)=-.545, \mathrm{p}>.05$, whereas class interval ranges from -.432 to .247 , and Cohen's $d=0.14$ which represent the small effect size.

Table 3

Comparison in Students' English proficiency After the intervention

\begin{tabular}{|c|c|c|c|c|c|c|c|c|c|}
\hline & \multicolumn{2}{|c|}{ Experimental } & \multicolumn{2}{|c|}{ Control } & \multirow[b]{2}{*}{$\mathrm{t}$} & \multirow[b]{2}{*}{$P$} & \multirow[b]{2}{*}{$d$} & \multicolumn{2}{|c|}{ Class Interval } \\
\hline & $\mathrm{M}$ & SD & $\mathrm{M}$ & SD & & & & Lower & Upper \\
\hline Reading & 6.28 & .945 & 5.03 & .615 & 6.061 & .000 & 1.6 & .836 & 1.660 \\
\hline Listining & 5.87 & .765 & 3.42 & .896 & 11.385 & .000 & 2.94 & 2.018 & 2.880 \\
\hline Grammar & 6.72 & 1.02 & 5.42 & .558 & 6.110 & .000 & 1.58 & .874 & 1.726 \\
\hline Proficiency & 6.29 & .467 & 4.62 & .476 & 13.675 & .000 & 3.54 & 1.421 & 1.909 \\
\hline
\end{tabular}

Independent sample $t$ test, that was utilized to measure the difference in mean scores in $8^{\text {th }}$ class students' English proficiency (reading, listening, and grammar) belonged to experimental and control groups. These values highlighted that after the intervention, there is an improvement in the language proficiency of students who belonged to the experimental group as compared to control group students' proficiency. $\mathrm{M}=6.29, \mathrm{SD}=.467$ of experimental group students is greater than the mean proficiency value $\mathrm{M}=4.62, \mathrm{SD}=.476$ of the control group. Similarly, $\mathrm{t}(58)=-.549$, $\mathrm{p}>.05$, whereas class interval ranges from 1.421 to 1.909 , and Cohen's $d=3.54$ which represent the large effect size.

\section{Table 4}

Comparison in Students' Achievement Results in English After the intervention

\begin{tabular}{|c|c|c|c|c|c|c|c|c|c|}
\hline & \multicolumn{2}{|c|}{ Experimental } & \multicolumn{2}{|c|}{ Control } & \multirow[b]{2}{*}{$t$} & \multirow[b]{2}{*}{$P$} & \multirow[b]{2}{*}{$d$} & \multicolumn{2}{|c|}{ Class Interval } \\
\hline & $\mathrm{M}$ & SD & $\mathrm{M}$ & SD & & & & Lower & Upper \\
\hline Achievement & 82.96 & 5.61 & 70.29 & 6.18 & 8.130 & .000 & 2.15 & 9.61 & 15.72 \\
\hline
\end{tabular}

Table 4 was about an independent sample $t$ test, that was incorporated to find the difference in mean scores in $8^{\text {th }}$ class students' English achievement through their term exams after completing the intervention. The values of the aforementioned table indicating that after the intervention students who were the part of experimental study achieve good scores in English, as $(\mathrm{M}=82.96, \mathrm{SD}=5.61)$ of experimental group students is greater than the mean achievement value $(\mathrm{M}=70.29, \mathrm{SD}=6.18)$ of the control group. Similarly, $\mathrm{t}(58)=-.545, \mathrm{p}>.05$, whereas class interval ranges from 9.61 to 15.72 , and Cohen's $d=2.15$ which represent the large effect size.

\section{Conclusion and Discussion}

The researchers draw the conclusion which is based on the above results. Cooperative learning is an effective teaching methodology that proves beneficial in the improvement of $8^{\text {th }}$ grade students' proficiency in English. These results are parallel with the results of a study that was carried out by Saleh (2012). He highlighted that cooperative learning brings positive improvement in proficiency as well as attitude towards learning of English among college students. These results are also consistent with findings highlighted by Suwantarathip and Wichadee (2010), as the results of their study showed that students produced better proficiency scores at the time of the post-test after experiencing the cooperative learning.

The results of current research also indicating that students secure good marks in their term exam of English after being part of the experimental group where students practiced cooperative learning. These results are well aligned with past reaches conducted by (Ahmad \& Mahmood, 2010; Ghaith, 2002; Gull \& Shehzad, 2015; Tran, 2014). 
The current intervention was carried out only for 10 weeks in this limited time duration researchers managed training, pre and post-test. Based on the findings it is recommended that future researchers may plan to deploy their intervention for a longer period that represents an improvement in students' proficiency and achievement in the long term. The results pointed out the improvement in students' achievement in English because of the utilization of cooperative learning as the teaching methodology. So, it is recommended that our teachers may use such innovative teaching methodologies in their classroom that not only promote students' involvement for discussion on the relevant topic, but it may also help to make it easier to understand the difficult concepts.

\section{References}

Ahmad, Z., \& Mahmood, N. (2010). Effects of cooperative learning vs. traditional instruction on prospective teachers' learning experience and achievement. Ankara Üniversitesi Ĕ̈itim Bilimleri Fakültesi Dergisi, 43(1), 151-164.

Astalini, Kurniawan, Kurniawan, \& Anggraini. (2019). Evaluation of Student's Attitude toward Science in Indonesia. Open Journal for Educational Research, 1-12.

Bury, J., \& Oka, T. (2017). Undergraduate students' perceptions of the importance of English in the tourism and hospitality industry. Journal of Teaching in Travel \& Tourism, 17(3), 173-188.

Chen, S.-F. (2005). Cooperative learning, multiple intelligences and proficiency: Application in college English language teaching and learning.

Emaliana, I. (2017). Teacher-centered or student-centered learning approach to promote learning? JURNAL SOSIAL HUMANIORA (JSH), 10(2), 59-70.

Farooq, S., Tatlah, I. A., \& Butt, I. H. (2020). Role of Peer Tutoring on the Intrinsic Motivation of Student Teachers in Pakistan: An Experimental Investigation.

Fujita, R. (2019). English for tourism and hospitality. Towards a New Paradigm for English Language Teaching, 172180.

Ghaith, G. M. (2002). The relationship between cooperative learning, perception of social support, and academic achievement. System, 30(3), 263-273.

Gull, F., \& Shehzad, S. (2015). Effects of cooperative learning on students' academic achievement. Journal of Education and Learning, 9(3), 246-255.

Hashmi, A., Khalid, M., \& Hussain, T. (2020). Effect of Cooperative Learning Approach on Students' Academic Achievement and Motivation at Secondary level. Global Social Sciences Review, 1, 479-411.

Ishikawa, T. (2017). Conceptualising English as a global contact language. Englishes in Practice, 4(2), 31-49.

Nejad, S. G., \& Keshavarzi, A. (2015). The effect of cooperative learning on reading comprehension and reading anxiety of pre-university students. Journal of Applied Linguistics and Language Research, 2(8), 169-180.

Poch, A. P., Carracedo, F. S., Salan, N., \& Alvarez, D. L. (2019). Cooperative learning and embedded active learning methodologies (C) for improving students' motivation and academic results. The International journal of engineering education, 35(6), 1851-1858.

Purba, A. N. (2018). The implementation of jigsaw cooperative learning technique in reading narrative text at third grade of smp xaverius 4 bandar lampung.

Saleh, M. I. (2012). The Effectiveness of Cooperative Learning on EFL Proficiency: A Case Study of Grade Ten Female Classroom in the New Developed High School Project in Riyadh, Saudi Arabia. (Master's Thesis), King Saud University, Saudi Arabia.

Sharan, Y. (2010). Cooperative learning for academic and social gains: Valued pedagogy, problematic practice. European Journal of Education, 45(2), 300-313.

Sharan, Y. (2015). Meaningful learning in the cooperative classroom. Education 3-13, 43(1), 83-94.

Suwantarathip, O., \& Wichadee, S. (2010). The impacts of cooperative learning on anxiety and proficiency in an EFL class. Journal of College Teaching \& Learning (TLC), 7(11), 51-58.

Tran, V. D. (2014). The effects of cooperative learning on the academic achievement and knowledge retention. International Journal of higher education, 3(2), 131-140.

Van Ryzin, M. J., \& Roseth, C. J. (2018). Cooperative learning in middle school: A means to improve peer relations and reduce victimization, bullying, and related outcomes. Journal of educational Psychology, 110(8), 1192.

Zarei, N., \& Sharna, C. (2019). Enhancing student-centred learning approach through group activities. Alford Council of International English \& Literature Journal(ACIELJ), 2(1), 11-16. 